\title{
Retinal detachment during COVID-19 era: a review of challenges and solutions
}

\author{
Amirhossein Roshanshad (D) - Susanne Binder
}

Received: 14 March 2021 / Accepted: 28 May 2021 / Published online: 30 June 2021

(C) Springer-Verlag GmbH Austria, ein Teil von Springer Nature 2021

\begin{abstract}
Summary
Background Since the beginning of the Coronavirus disease 2019 (COVID-19) pandemic, there have been obstacles in the proper diagnosis and management of many diseases. We evaluated the changes in retinal detachment $(\mathrm{RD})$ presentation and surgery during the COVID-19 pandemic and propose solutions to minimize the detrimental effects of lockdown on RD diagnosis.

Materials and methods PubMed, Embase, Scopus, Web of Science, and Google Scholar were searched for relevant articles with the keywords "Retinal detachment" AND "Coronavirus OR COVID-19 OR SARS OR MERS."

Results The COVID-19 lockdown was associated a $53-66 \%$ reduction in $\mathrm{RD}$ presentation. The decrease in the rate of macula-on $\mathrm{RD}$, the increase in the mean duration of symptoms, and the rise in the number of patients with proliferative vitreoretinopathy were all suggestive of a delayed presentation of RD. Moreover, a drop of $56-62 \%$ in RD repair surgeries was observed. However, the most frequently performed ophthalmic surgery changed from cataract surgery in April 2019 to $\mathrm{RD}$ repair in April 2020. Using phacovitrectomy
\end{abstract}

\footnotetext{
A. Roshanshad, MD ( $\square)$

Student Research Committee, Shiraz University of Medical Sciences, Shiraz, Iran

MPH Department, School of Medicine, Shiraz University of Medical Sciences, Shiraz, Iran

Aroshanshad@gmail.com

\section{S. Binder, MD}

Department of Ophthalmology, Sigmund Freud University, Vienna, Austria

Department of Ophthalmology, Weill Cornell Medicine, New York, USA

susanne@susannebinder.com
}

instead of vitrectomy alone can reduce the number of operations in ophthalmology centers, decrease the use of personal protective equipment by $50 \%$, and cut costs per patient by $17-20 \%$. Also, developing a wellorganized telemedicine system can decrease unnecessary visits and delayed presentations.

Conclusion Delay in RD presentation and surgery is associated with a poorer prognosis. Optimizing the guidelines of RD management and developing a wellorganized telemedicine system can minimize the impact of lockdown on $\mathrm{RD}$ management.

Keywords Presentation - Telemedicine • Vitrectomy • Delayed diagnosis · Macula-on

\section{Netzhautabhebung während der Corona- Pandemie: Überblick über Herausforderungen und Lösungen}

\section{Zusammenfassung}

Hintergrund Seit Beginn der Coronavirus-Pandemie 2019 (COVID-19) sind Diagnose und Therapie vieler Erkrankungen mit großen Problemen konfrontiert. In der vorliegenden Arbeit wurden die Veränderungen bei der primären Diagnostik von Netzhautabhebungen und beim chirurgischen Prozedere während der COVID-19-Pandemie erhoben. Lösungsansätze zur Minimierung negativer Auswirkungen eines Lockdowns für Diagnose und Therapie von Netzhautabhebungen werden vorgestellt.

Material und Methode Die Datenbanken PubMed, Embase, Scopus, Web of Science und Google Scholar wurden mit den Schlüsselwörtern „Netzhautabhebung“ und "Coronavirus oder COVID 19 oder SARS oder MERS“" auf relevante Artikel hin durchsucht. Ergebnisse Während des COVID-19-Lock-downs kam es zu einer Reduktion von 53-66\% bei der primären 
Diagnose von Netzhautabhebungen. Für die verspätete Vorstellung von Patienten mit Netzhautabhebung sprechen der höhere Anteil von Netzhautabhebungen mit präoperativ bereits abgehobener Makula („macula-off"), eine längere Dauer der Symptomatik und die größere Zahl von Patienten mit proliferativer Vitreoretinopathie. Parallel dazu wurde eine Reduktion um 56-62 \% bei Netzhautoperationen verzeichnet, obwohl die häufigste Augen-Op. im April 2019 die (elektive) Katarakt-Op. und im April 2020 die Ablations-Op. war. Durch die kombinierte Katarakt-Op. mit Vitrektomie lässt sich die Op.-Gesamtzahl reduzieren. Dies könnte den Verbrauch von protektivem Material für das Personal um $50 \%$ senken und die Kosten pro Patient um etwa $17-20 \%$. Ein gut organisiertes Telemedizinsystem kann zur Reduktion unnötiger Arztbesuche, aber auch einer verzögerten Diagnosestellung beitragen.

Schlussfolgerung Die Verzögerung von Diagnose und Therapie einer Netzhautabhebung geht mit schlechterer Prognose einher. Die Richtlinien des Managements von Netzhautabhebungen zu optimieren und ein gut organisiertes telemedizinisches Netzwerk zu entwickeln, könnten die Auswirkungen eines Lockdowns in der Behandlung von Netzhautabhebungen minimieren.

Schlüsselwörter Präsentation · Telemedizin . Vitrektomie · Verspätete Diagnose · Anliegende Makula

\section{Background}

Retinal detachment (RD) is an ophthalmic emergency characterized by separation of the neurosensory retina from the underneath retinal pigment epithelium [1]. With an annual incidence of 12.05-18.2 per 100,000, rhegmatogenous RD (RRD) remains one of the causes of irreversible vision loss [2, 3]. Myopia, cataract removal, and trauma are the main risk factors for RD. Response to treatment is determined by several factors: Involvement of the macula (macula-on $\mathrm{RD}$ ), higher extent of retinal detachment, proliferative vitreoretinopathy (PVR), and longer duration of $\mathrm{RD}$ before surgery are associated with poorer response to treatment [4-7]. Therefore, early diagnosis and management of $\mathrm{RD}$ is crucial.

From the beginning of 2020 and the Coronavirus Disease 2019 (COVID-19) pandemic, proper diagnosis and treatment of many diseases has faced serious obstacles $[8,9]$. This situation became worse after implementation of lockdown rules by many countries. Retinal detachment is of great importance due to the necessity of emergent diagnosis and management. Delayed management of $\mathrm{RD}$ is accompanied by progression to severe stages, which are mainly irreversible. Therefore, in this study, we comprehensively reviewed the available literature and discuss different aspects of changes in presentation, diagnosis, and management of RD during the COVID-19 era.

\section{Materials and methods}

We searched PubMed, Embase, Scopus, Web of Science, and Google Scholar with the keywords "Retinal detachment" AND "Coronavirus OR COVID-19 OR SARS OR MERS." In this study, we focus mainly on the impact of COVID-19 on changing the presentation, diagnosis, and management of RD. We also consider the advantages of phacovitrectomy over vitrectomy alone for management of RD in reducing costs. Finally, we discuss the role of telemedicine in minimizing the detrimental effects of lockdown rules on diagnosing and managing RD during the COVID-19 pandemic. We propose the following research areas to ascertain that we have collected enough papers to cover different aspects of RD during the COVID-19 pandemic.

- Changes in presentation of $\mathrm{RD}$ and the stage at which $\mathrm{RD}$ is diagnosed

- Changes in RD treatment surgeries

- Phacovitrectomy instead of vitrectomy for treatment of RD

- Role of telemedicine in RD during the COVID-19 era

\section{Results}

Overall, 280 articles were found in the initial search. After removal of the duplicates, 183 titles and abstracts were screened. The full texts of 32 articles were evaluated and eight papers were finally included in our review. Details are presented in Fig. 1.

\section{Changes in the patterns of presentation of $R D$ during} COVID-19 era

The COVID-19 lockdown was associated with a decrease in $\mathrm{RD}$ presentations to clinics as well as with changes in the patterns of RD presentation.

Different studies reported an approximately $53-66 \%$ decrease in $\mathrm{RD}$ patients presenting to ophthalmology clinics ([10-13]; Table 1). Likewise, a $60 \%$ and $64.9 \%$ drop was reported in the number of retinal tears and posterior vitreous detachment (PVD) cases, respectively [11]. It was mentioned that cancelation of visits by the patients was the most important reason (84\%) for this reduction in the number of ophthalmic cases [14]. A reduced presentation of RD and cancellation of visits can be attributed to several factors. Fear of attending ophthalmology clinics during the COVID19 pandemic seems to be the leading reason. Besides, the closure of many clinics and limitations caused by implementation of lockdown rules made it difficult for some patients to attend the clinics [12-16].

The pattern of RD presentation has also changed during the pandemic. It has been shown that a higher proportion of $\mathrm{RD}$ patients are diagnosed with maculaoff RD during the COVID-19 pandemic compared with the same period in 2019 in the United States $(44 \%$ in 2019 vs. $63.6 \%$ in 2020 ; [15]). These changes in patterns of RD presentation were also observed in a study 
Fig. 1 Flow diagram of the included studies
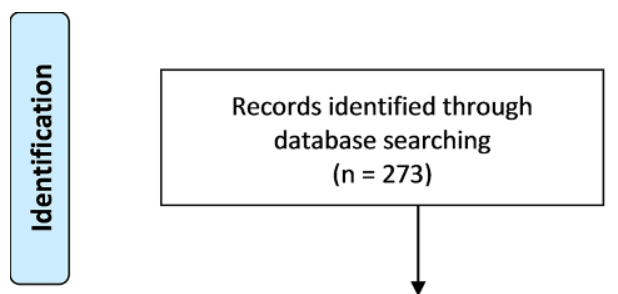
( $n=273$ )
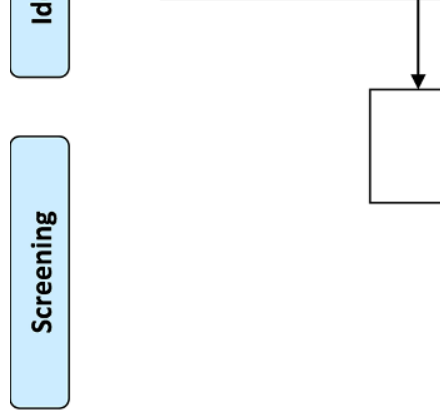

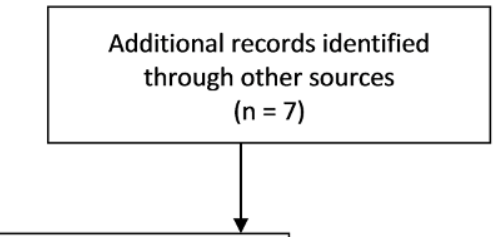

Records after duplicates removed ( $n=183$ )
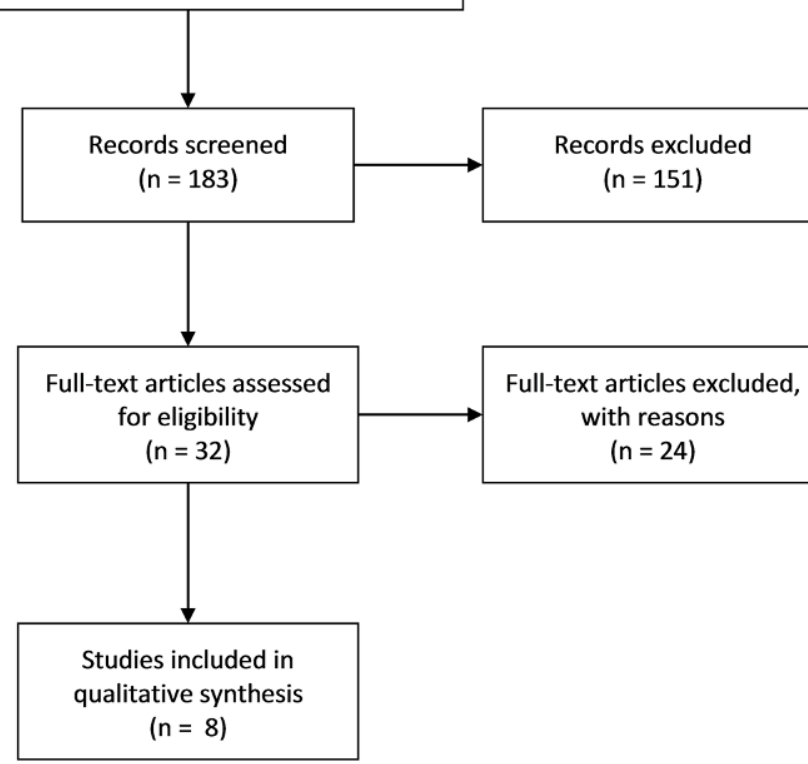

( $n=24$ )

lated issues globally. However, researchers from other countries are encouraged to disseminate the results of their experiences of lockdown. By comparing the results of different studies, the optimal approach to lockdown with lowest impact on healthcare systems can be identified.

\section{Changes in RD treatment surgery during the COVID- 19 era}

The decrease in the number of $\mathrm{RD}$ patients resulted in a reduction in $\mathrm{RD}$ surgeries: a $56-62 \%$ decrease in $\mathrm{RD}$ treatment surgeries was reported in the studies [15, 18]. Similarly, a 50\% decline in RD cases needing laser therapy was reported [15]. Initially, it was anticipated that due to the closure of many peripheral centers during lockdown, referral centers would face a surge in the number of RD cases and surgeries. However, the opposite pattern was seen after implementation of isolation measures. Apart from the fear of more exposure to COVID-19 in hospital settings, many patients who routinely visit optometrists are not familiar with alternatives following the closure of many optometry centers. Therefore, we anticipate a surge in $\mathrm{RD}$ cases, especially complicated and untreated cases after lifting of the lockdown rules. 
Table 1 Studies of change in the patterns of presentation for retinal detachment (RD) and vitreoretinal surgery during the COVID-19 era

\begin{tabular}{|c|c|c|c|c|}
\hline First author & Year & Types of the paper & Location & Findings \\
\hline Rohl [15] & 2020 & Letter & $\begin{array}{l}\text { United } \\
\text { States }\end{array}$ & $\begin{array}{l}56 \% \text { decrease ( } 25 \text { in } 2019 \text { vs. } 11 \text { in } 2020 \text { ) in number of retinal detachment surgeries } \\
50 \% \text { decrease ( } 16 \text { in } 2019 \text { vs. } 8 \text { in 2020) in retinal tears and holes needing laser therapy during the } \\
\text { COVID-19 lockdown period } \\
\text { Increase in patients presenting with macula-off RD ( } 44 \% \text { in } 2019 \text { vs. } 63.6 \% \text { in } 2020 \text { ) }\end{array}$ \\
\hline Wickham [18] & 2020 & Comment & $\begin{array}{l}\text { United } \\
\text { Kingdom }\end{array}$ & $62 \%$ decrease in the number of retinal detachment surgeries during lockdown period \\
\hline Pelligrini [12] & 2020 & Letter & Italy & $64 \%$ decrease ( 22 in 2019 vs. 8 in 2020 ) in RD cases \\
\hline Awad [10] & 2020 & $\begin{array}{l}\text { Letter (retrospec- } \\
\text { tive case review) }\end{array}$ & $\begin{array}{l}\text { United } \\
\text { Kingdom }\end{array}$ & $\begin{array}{l}60 \% \text { decrease in RD presentation ( } 92 \text { in } 2019 \text { vs. } 37 \text { in } 2020 \text { ) } \\
\text { Increase in mean symptom duration ( } 14.8 \text { days in } 2019 \text { vs. } 22.5 \text { days in } 2020, p=0.2297 \text { ) } \\
\text { Decrease in proportion of patients with macula-on RD ( } 47.8 \text { in } 2019 \text { vs. } 32.4 \% \text { in } 2020, p=0.1210 \text { ) } \\
\text { Significant increase in cases presenting with PVR ( } 9.8 \text { in } 2019 \text { vs. } 24.3 \% \text { in } 2020, p=0.0471 \text { ) }\end{array}$ \\
\hline Poyser [11] & 2020 & Letter & $\begin{array}{l}\text { United } \\
\text { Kingdom }\end{array}$ & $\begin{array}{l}60 \% \text { ( } 15 \text { in } 2019 \text { vs. } 6 \text { in } 2020 \text { ) decrease in the number of retinal tears. } 64.9 \% \text { ( } 131 \text { in } 2019 \text { vs. } 46 \text { in } \\
2020 \text { ) decline in PVD } \\
65.7 \% \text { ( } 35 \text { in } 2019 \text { vs. } 12 \text { in } 2020 \text { ) decrease in number of RD } \\
\text { Higher proportion of macula-off RD in } 2020 \text { compared with } 2019 \text { ( } 42.9 \% \text { in } 2019 \text { vs. } 84.6 \% \text { in } 2020 \text { ) }\end{array}$ \\
\hline Veritti [27] & 2020 & Review & Italy & $\begin{array}{l}68 \% \text { ( } 471 \text { in } 2019 \text { vs. } 151 \text { in 2020) decrease in the number of non-deferrable surgeries (including RD, } \\
\text { glaucoma, ocular oncology surgeries) and intravitreal injections }\end{array}$ \\
\hline Starr [17] & 2020 & Cross sectional & $\begin{array}{l}\text { United } \\
\text { States }\end{array}$ & $\begin{array}{l}\text { More private centers were able to see patients for PVD visit ( } 75 \% \text { vs. } 40 \%) \text {; however, no statistically } \\
\text { significant differences were observed between private and university centers in terms of time to next } \\
\text { available PVD visit and percentage of receptionists who asked the patients about COVID-19 symptoms. } \\
\text { Also, no significant differences were observed between centers located in areas with high or low preva- } \\
\text { lence of COVID-19 in terms of the mentioned outcomes }\end{array}$ \\
\hline Shams [13] & 2020 & Letter & Scotland & $\begin{array}{l}52.7 \% \text { decrease ( } 18.2 \text { vs. } 8.6) \text { in mean weakly and annual incidence of RRD before and after lockdown } \\
\text { decrease in proportion of patients with macula-on RD }(41.9 \% \text { vs. } 34.9 \%) \text { before and after lockdown }\end{array}$ \\
\hline
\end{tabular}

\section{Phacovitrectomy instead of vitrectomy}

The COVID-19 pandemic has affected not only the diagnosis of many ocular diseases, but also the management of some ophthalmic problems. Vitrectomy is the most frequently performed vitreoretinal surgery, used for the treatment of many posterior segment disorders. Nuclear sclerotic cataract formation is one of the most common complications of vitrectomy, progressing, in particular, in the first few years following vitrectomy $[19,20]$. In contrast to cataract surgeries, $\mathrm{RD}$ repair is considered an ophthalmic emergency. Therefore, it is anticipated to observe an increase in the rate of $\mathrm{RD}$ repair surgeries and a decrease in non-emergent surgeries like cataract removal. Al-Khersan et al. compared the number of emergent ophthalmic surgical procedures during April 2020 and April 2019 [21]. The total number of surgeries decreased significantly (117 in 2020 vs. 1107 in 2019, $p<0.0001$ ). In April 2019, 481 elective cataract surgeries were performed, comprising $47.3 \%$ of total surgeries. In April 2020, on the other hand, the most widely performed ophthalmic surgery was RD repair, accounting for $31.6 \%$ of total procedures. However, due to the vision impairment caused by post-vitrectomy cataract formation and the prolonged duration of the COVID-19 pandemic and lockdown, even non-emergent surgeries like cataract removal may be inevitable to maintain the quality of life of the patients. It seems reasonable to perform phacovitrectomy instead of vitrectomy alone whenever possible to minimize the number of visits and operations in ophthalmology centers [22]. Also, this combined procedure decreases the use of personal protective equipment (PPE) by $50 \%$ compared with sequential surgery and saves costs per patients by $17-20 \%$ [23].

\section{Usefulness of telemedicine in ophthalmology during the COVID-19 era}

McCord et al. reported two cases of RD diagnosed via tele-ophthalmology [24]. In a review article, Sommer et al. assessed the role of telemedicine in ophthalmology and concluded that telemedicine can be useful for diagnosing, screening, and management of anterior segment problems, glaucoma, and retinal diseases [25]. Retinopathy of prematurity, diabetic retinopathy, and macular degeneration are among the most well-known retinal diseases evaluated by telemedicine. Their review suggested that in the lockdown era due to the COVID-19 pandemic and the decreased presentations of many ocular conditions, tele-ophthalmology can play a fundamental role in screening, diagnosing, and managing many ocular conditions, especially ophthalmic emergencies. Telemedicine can identify at-risk patients and encourage them to attend ophthalmology clinics for more evaluation. This planned selection of high-risk patients not only decreases unnecessary visits to ophthalmology centers but also reduces the number of cases with delayed presentations.

Overall, these changes in the pattern of RD presentation occurred during the first wave of COVID19 and lockdown and can be repeated in the next 
peaks. Herein, we recommended phacovitrectomy instead of sequential surgery to reduce the workload and crowdedness in ophthalmology clinics. Besides, the economic impact of COVID-19 has led many countries to find ways of reducing costs [26]. Combined surgery can cut down on expenses and save PPE, as mentioned earlier. Also, healthcare authorities should inform people about medical conditions and symptoms that necessitate urgent diagnosis and management. This can improve patients' awareness of the early symptoms of RD and decrease the rate of delayed presentation of RD. Finally, we propose developing a well-organized method of telemedicine, capable of distinguishing at-risk patients for RD in order to decrease expenses and the aggregation of patients in clinics. Telemedicine can also help to better identify RD patients and prevent delayed diagnosis and management of RD. The recommendations that we mention in this article can be generalized for the next waves of COVID-19 and even for future epidemics and pandemics. Therefore, a well-organized method of telemedicine not only can help humankind in the COVID-19 pandemic but also may be lifesaving in future crises.

\section{Conclusion}

COVID-19 has affected the diagnosis and management of retinal detachment (RD) worldwide. Delayed presentation of RD in its severe stages after implementation of lockdown is associated a poorer prognosis. Tele-ophthalmology can help ophthalmologists to screen at-risk patients, which will in turn decrease the rate of late diagnosis of ophthalmic emergencies and reduce the workload of ophthalmology clinics. Besides, there is an essential need for reorganization of ophthalmology services and surgery guidelines so as to minimize the impact of lockdown on ophthalmic patients.

Author Contribution Conceptualization: [Amirhossein Roshanshad]; Methodology: [Amirhossein Roshanshad, Susanne Binder]; Literature search: [Amirhossein Roshanshad]; Writing-original draft preparation: [Amirhossein Roshanshad]; Writing-review and editing: [Amirhossein Roshanshad, Susanne Binder]; Supervision: [Susanne Binder]

Conflict of interest A. Roshanshad and S. Binder declare that they have no competing interests.

\section{References}

1. D'Amico DJ. Primary retinal detachment. N Engl J Med. 2008;359(22):2346-54.

2. Mitry D, Charteris DG, Yorston D, et al. The epidemiology and socioeconomic associations of retinal detachment in Scotland: a two-year prospective population-based study. Invest OphthalmolVis Sci. 2010;51(10):4963-8.

3. van de Put MA, Hooymans JM, Los LI, Group DRRDS. The incidence of rhegmatogenous retinal detachment in The Netherlands. Ophthalmology. 2013;120(3):616-22.
4. Salicone A, Smiddy WE, Venkatraman A, Feuer W. Visual recovery after scleral buckling procedure for retinal detachment. Ophthalmology. 2006;113(10):1734-42.

5. Tseng W, Cortez RT, Ramirez G, Stinnett S, Jaffe GJ. Prevalence and risk factors for proliferative vitreoretinopathy in eyes with rhegmatogenous retinal detachment but no previous vitreoretinal surgery. Am J Ophthalmol. 2004;137(6):1105-15.

6. Tani P, Robertson DM, Langworthy A. Prognosis for central vision and anatomic reattachment in rhegmatogenous retinal detachment with macula detached. Am J Ophthalmol. 1981;92(5):611-20.

7. Park DH, Choi KS, Sun HJ, Lee SJ. Factors associated with visual outcome after macula-off rhegmatogenous retinal detachment surgery. Retina. 2018;38(1):137-47.

8. Dinmohamed AG, Visser O, Verhoeven RH, et al. Fewer cancer diagnoses during the COVID-19 epidemic in the Netherlands. Lancet Oncol. 2020;21(6):750-1.

9. Jones D, Neal RD, Duffy SR, Scott SE, Whitaker KL, Brain K. Impact of the COVID-19 pandemic on the symptomatic diagnosis of cancer: the view from primary care. Lancet Oncol. 2020;21(6):748.

10. Awad M, Poostchi A, Orr G, Kumudhan D, Zaman A, WildeC. Delayed presentation and increased prevalence of proliferativevitreoretinopathyforprimary rhegmatogenous retinal detachments presenting during the COVID-19 pandemic lockdown. Eye (Lond). 2020;35(4):1282-1283.

11. Poyser A, Deol SS, Osman L, et al. Impact of COVID19 pandemic and lockdown on retinal detachments. Eye (Lond). 2020. https://doi.org/10.1038/s41433-020-01137$\mathrm{x}$

12. Pellegrini M, Roda M, Lupardi E, Di Geronimo N, Giannaccare G, Schiavi C. The impact of COVID-19 pandemic on ophthalmological emergency department visits. Acta Ophthalmol. 2020. https://doi.org/10.1111/aos.14489

13. Shams F, El-Abiary M, Goudie C, Yorston D. Effects of lockdown on retinal detachment incidence in Scotland. Eye. 2020;35(4):1279-1280.

14. Hattenbach LO, Heinz P, Feltgen N, et al. Impacts of the SARS-CoV-2 pandemic on ophthalmic care in Germany. Ophthalmologe. 2020;117(9):892-904.

15. Rohl A, Kalhorn A, Singh J, Mandava N. Decreased retinal detachments during a COVID-19 lockdown period in Colorado. Acta Ophthalmol. 2020. https://doi.org/10.1111/ aos. 14570

16. Roshanshad A, Ashraf MA, Roshanshad R, Kharmandar A, ZomorodianSA, AshrafH. Ocularmanifestations of patients with Coronavirus disease 2019: a comprehensive review. JOphthalmic Vis Res. 2021;16(2):234-247.

17. Starr MR, Israilevich $R$, Zhitnitsky $M$, et al. Practice patterns and responsiveness to simulated common ocular complaints among US ophthalmology centers during the COVID-19 pandemic. JAMA Ophthalmol. 2020;138(9):981-988. https://doi.org/10.1001/ jamaophthalmol.2020.3237.

18. Wickham L, Hay G, Hamilton R, et al. The impact of COVID policies on acute ophthalmology services-experiences from Moorfields Eye Hospital NHS Foundation Trust. Eye. 2020;34(7):1189-92.

19. Belin PJ, Parke DW III. Complications of vitreoretinal surgery. Curr Opin Ophthalmol. 2020;31(3):167-73.

20. Do DV, Gichuhi S, Vedula SS, Hawkins BS. Surgery for postvitrectomy cataract. Cochrane Database Syst Rev. 2013; https://doi.org/10.1002/14651858.CD006366.pub4.

21. Al-Khersan H, Kalavar MA, Tanenbaum R, et al. Emergent ophthalmic surgical care at a tertiary referral center during the COVID-19 pandemic. Am J Ophthalmol. 
2020;222:368-372. https://doi.org/10.1016/j.ajo.2020.08. 044

22. Antaki F, Milad D, Javidi S, Dirani A. Vitreoretinal surgery in the post-Lockdown era: making the case for combined phacovitrectomy. Clin Ophthalmol. 2020;14:2307-9.

23. Seider MI, Lahey JM, Fellenbaum PS. Cost of phacovitrectomy versus vitrectomy and sequential phacoemulsification. Retina. 2014;34(6):1112-5.

24. McCord SA, Lynch MG, Maa AY. Diagnosis of retinal detachments by a tele-ophthalmology screening program. J Telemed Telecare. 2019;25(3):190-2.

25. Sommer AC, Blumenthal EZ. Telemedicine in ophthalmology in view of the emerging COVID-19 outbreak. Grae- fes Arch Clin Exp Ophthalmol. 2020;258(11):2341-2352. https://doi.org/10.1007/s00417-020-04879-2

26. Baldwin R, Weder di Mauro B. Economics in the Time of COVID-19. : CEPR Press; 2020.

27. Veritti D, Sarao V, Bandello F, Lanzetta P. Infection control measures in ophthalmology during the COVID-19 outbreak: A narrative review from an early experience in Italy. EurJOphthalmol. 2020;30(4):621-8.

Publisher's Note Springer Nature remains neutral with regard to jurisdictional claims in published maps and institutional affiliations. 